\title{
Influence of Demographic and Reproductive Factors on Cervical Pre-Cancer and Cancer in Bangladesh
}

\author{
Ashrafun Nessa ${ }^{1 *}$, Rowson Ara ${ }^{2}$, Parveen Fatema ${ }^{2}$, Begum Nasrin ${ }^{2}$, Afroza \\ Chowdhury ${ }^{2}$, Kamrul Hasan Khan ${ }^{3}$, Ashim Ranjan Barua ${ }^{3}$, Mohammad Harun \\ Ur Rashid ${ }^{4}$
}

\begin{abstract}
Background: In Bangladesh, cervical cancer (CC) is the 2nd most common cancer with estimated 8068 new cases and 5,214 deaths every year. It is also revealed that different socio-demographic factors have association with CC. This study was performed to evaluate the colposcopy outcomes and the association of different demographic and reproductive risk factors with cervical pre-cancer and cancer. Methods: This retrospective cross-sectional study was carried out at the colposcopy clinic of Bangabandhu Sheikh Mujib Medical University (BSMMU) between January 2010 and December 2016. Results: A total 16147 women attended the colposcopy clinic of BSMMU with VIA positive reports. Among them, $65.73 \%$ women were referred from different VIA centers of Dhaka district. Mean age of marriage of the subjects was $16.93( \pm 1)$ and mean age of 1 st delivery was 18.45 years $( \pm 4.10)$. Almost three-fourth of them were married before 18 years and had their 1st delivery by 20 years. Colposcopy examination of the VIA positive women revealed that $36.7 \%$ had CINI, $10.6 \%$ had CINII/ III and $7.1 \%$ had carcinoma of cervix. Considering CIN as disease the Sensitivity, Specificity, PPV and NPV of colposcopy were found $99.7 \%, 75.3 \%, 70.3 \%$ and $99.8 \%$ respectively. On other hand considering CIN2+ as disease the Sensitivity, Specificity, PPV and NPV of colposcopy were found $73.8 \%, 92.7 \%, 64.4 \%$ and $95.2 \%$ respectively. Statistical analysis revealed that higher age $(\mathrm{p}=0.000)$, lower level of education ( $\mathrm{p}=0.007)$, lower socioeconomic status $(\mathrm{p}=0.014)$, higher parity $(\mathrm{p}=0.001)$ had individual influence on cervical pre-cancer and cancer. Conclusions: This study indicated higher age, low level of education, lower socio-economic condition and higher parity as most important socio-demographic factors for developing cervical pre-cancer and cancer in Bangladesh.
\end{abstract}

Keywords: Influence- demographic- reproductive- factors- cervical- pre-cancer- cancer- Bangladesh

Asian Pac J Cancer Prev, 21 (7), 1883-1889

\section{Introduction}

Cervical cancer $(\mathrm{CC})$ is the fourth most frequent cancer in women with an estimated 570,000 new cases in 2018 representing $6.6 \%$ of all female cancers. Approximately $90 \%$ of deaths CC occurred in low- and middle-income countries (Bray et al., 2018). In Bangladesh, CC is the 2nd most common cancer among women, with age-standardized rates (ASRs) for incidence less than the global average (10.6 vs. 13.1/100,000 women) and mortality higher than the global average statistics (7.1 vs. $6.9 / 100,000$ women). It is estimated that every year 8068 new cases of $\mathrm{CC}$ are detected in Bangladesh and 5,214 women die of the disease (Ferlay et al., 2018). International Agency for Research on Cancer. Available $\mathrm{CC}$ is caused by human papilloma virus (HPV), a sexually transmitted virus, which is one of the most common viral infections of the reproductive tract. Survival of CC patients are strongly determined by stage at diagnosis. Due to the late stage at diagnosis and inadequate management facilities, mortality rates from cancer cervix are high in Bangladesh.

The Government of Bangladesh (GOB) has developed $\mathrm{CC}$ screening program up to district and selected sub-district (upazila) level and Visual Inspection of Cervix with Acetic Acid (VIA) is considered as a method of screening of CC. VIA is performed at Upazila Health Complexes (UHCs), Maternal and Child Welfare Centers (MCWCs), District Hospitals (DHs), Medical College Hospitals (MCHs) and BSMMU by trained Family Welfare Visitors (FWVs), Senior Staff Nurses (SSNs) and Doctors. The programme offers VIA method for ever

${ }^{1}$ Department of Gynaeclogical Oncology, Bangabandhu Sheikh Mujib Medical University (BSMMU), Shahbag, Dhaka-1000, Bangladesh. 2Department of Obstetrics and Gynaecology, BSMMU, Shahbag, Dhaka-1000, Bangladesh. ${ }^{3}$ Department of Histopathology, BSMMU, Shahbag, Dhaka-1000, Bangladesh. ${ }^{4}$ Institute of Epidemiology, Diseese Control and Research (IEDCR), Directorate General of Health Services, Mohakhali, Dhaka-1212, Bangladesh. *For Correspondence: ashra58@yahoo.co.uk 
married women of 30 years and above. Till now about 375 VIA centers has already been established at primary, secondary and tertiary level health care facilities of 64 districts of Bangladesh. Women with VIA-ve report are advised to have repeat test after 3 years and women with VIA+ve reports are being referred to the colposcopy clinic of BSMMU and other government MCHs for evaluation and management (Nessa et al., 2013, Holme et al., 2017, Nessa et al., 2010). The referral centers have facilities for colposcopy, histopathology and management of precancerous condition of the cervix. Almost all cases of CC are caused by certain strains of HPV and have been etiologically linked to both pre-invasive lesions and invasive cervical carcinoma (Lizano et al., 2009). It is also revealed that different socio-demographic and reproductive factors have association with $\mathrm{CC}$. Epidemiological studies conducted during the past 30 years have consistently indicated that CC risk is strongly influenced by measures of sexual activity, number of sexual partners, age at first sexual intercourse and sexual behavior of the women's male partners (Remschmidt et al., 2013). There were inadequate information for finding out the influence of demographic and reproductive factors on CC risk in Bangladesh. This study was performed to evaluate the influence of different demographic and reproductive risk factors for developing cervical precancer and cancer among women attending the colposcopy clinic of BSMMU with VIA positive reports.

\section{Materials and Methods}

This retrospective cross-sectional and hospital based study was carried out at the colposcopy clinic of BSMMU between January 2010 and December 2016. In the mentioned period, 16,147 women with VIA positive reports attended colposcopy clinic of BSMMU. Data were collected during first and follow-up visits and recorded in the colposcopy registrars at colposcopy clinic by face to face interview from these women. For demographic variables, the districts (residing district of women), age, education of women, occupation of women, occupation of husband and socio-economical status (based on monthly family income) were considered. On the other hand, parity, age of marriage and age of delivery were considered as reproductive variables in this study.

All women had colposcopic examination by experienced colposcopist using standard colposcopes (Karl Kaps Som 52 or Leisegang 1DF) after receiving verbal consent. The results of the biopsies were also recorded in the colposcopy registry books. From January 2012, colposcopy clinic of BSMMU is following Swede score for management of women. Previously modified Reid score used to guide colposcopy diagnosis.

The quality of the colposcopy centres were well monitored, Postgraduate gynaecologists/SSNs from different MCHs/ BSMMU/ DHs received basic colposcopy training for 12 days from BSMMU. During the training "Colposcopy and Treatment of Cervical Intraepithelial Neoplasia: A beginners Manual" on colposcopy and treatment of CIN published by International Agency for Research on Cancer (IARC) was used as the training guideline. Advanced colposcopy training was given to practicing colposcopists. Colposcopists attended a course on 'Early Detection and Prevention of CC' at Barshi jointly organized and facilitated by IARC, a Tata Memorial Centre Rural Cancer Project at Nargis Dutt Memorial Cancer Hospital, Barshi, and GOB in 2016. Histological Diagnosis was made on histology findings of specimens collected by punch biopsy forceps/ LEEP in colposcopy suspected CIN cases. All Histology examinations were done in the Department of Pathology of BSMMU and each slide was reviewed by at least two competent Histopathologist. Histology report was done by a board of the department in the cases of diagnostic disparity.

The final diagnosis was done by the histopathology report. Women with cervical intraepithelial neoplasia (CIN) I lesions were advised for follow-up after one year. However, the women were offered treatment if she desired or there was risk of failure of follow up. Women with CIN II or higher lesions were offered treatment during the same visit by loop electrical excision procedure (LEEP) or thermo-coagulation after collection of tissue for histological examination. Women with invasive cancers were referred to gynae-oncology for further management.

Data were collected retrospectively from the colposcopy registry books and entered into SPSS for analysis. The baseline characteristics of the women were summarized using means and frequencies. Detection rates of CIN I, CIN II, CIN III, Ca-cervix, normal findings, as well as demographic data were calculated. CIN II and III considered as pre-cancer. Sensitivity, specificity, positive predictive value (PPV) and negative predictive value (NPV) were calculated for colposcopy findings considering histopathology findings as gold standard. Low grade squamous intraepithelial lesion (LSIL, also known as CIN1) is now recognized as a histological diagnosis of benign viral replication that should be managed conservatively (Tainio et al., 2018). Under current clinical guidelines recommended by WHO, women with cervical intraepithelial neoplasia (CIN1) are to be monitored (WHO, 2006). The sensitivity, specificity, PPV and NPV were calculated in two conditions; first one was CIN as disease and second one was CIN2+ as disease, in both conditions women with unavailable histopathology results were excluded. The study was approved by the Institutional Review Board of BSMMU.

\section{Results}

Among 16,147 women with VIA positive cards at the colposcopy clinic of BSMMU from January 2010 to December 2016, more than half attended from different VIA and CBE centers of Dhaka (65.7\%). Remaining women attended from other nearer districts like Narsingdi (4.7\%), Narayanganj (3.5\%), B. Baria (3.4\%), Gazipur (3.0\%), Manikganj (2.6\%), Comilla (2\%) and other 57 districts (14.7\%). Among the VIA+ve women at BSMMU colposcopy clinic, 9,733 (60.3\%) women were referred from VIA and CBE center of BSMMU, 2,832 (17.5\%) from different sub-districts (UHCs) and 1,620 (10.0\%) from different District Hospitals (Table 1).

Majority of the VIA+ve women 10,927 (67.7\%) were 
Table 1. Distribution of Districts and VIA and CBE Centers of the Attending Women

\begin{tabular}{lc}
\hline Particulars & Number (\%) \\
\hline Name of Districts & $10,614(65.7)$ \\
Dhaka & $764(4.7)$ \\
Narsingdi & $566(3.5)$ \\
Narayanganj & $556(3.4)$ \\
B.Baria & $484(3.0)$ \\
Gazipur & $431(2.6)$ \\
Manikganj & $354(2.2)$ \\
Comilla & $2,378(14.7)$ \\
Other 57 districts & \\
Name of VIA and CBE Centres & $9,733(60.3)$ \\
Bangabandhu Sheikh Mujib Medical & \\
University (BSMMU) & $2,832(17.5)$ \\
Upazila Health Complexes (UHCs) & $1,620(10.0)$ \\
District Hospitals (DHs) & $1,072(6.6)$ \\
Maternal and Child Welfare Centres & \\
(MCWCs) & $489(3.0)$ \\
Medical College Hospitals (MCHs) & $401(2.5)$ \\
NGOs &
\end{tabular}

*Percentage within parenthesis, ; a) VIA- Visual Inspection of Cervix with Acetic Acid; b) CBE- Clinical Breast Examination

between 30-49 years and 1,455 (9.0\%) were more than 50 years of age. Though a good number $(66.2 \%)$ had at least primary ( 5 years of schooling) education, only $22.6 \%$ had secondary (10 years of schooling) education and above. Majority of the women were housewives. Mean age of marriage was 16.9 years $( \pm 3.1)$ and mean age of $1 \mathrm{st}$ delivery was 18.45 years $( \pm 4.1)$. About three-fourth of the women were married before 18 years of age $(74.4 \%)$ and had their $1^{\text {st }}$ delivery by 20 years $(76 \%)$. The Mean parity of the women was $2.6(+1.4)$ (Table 2).

Among the 16,147 VIA positive women, 7,226 (44.7\%) had normal finding during colposcopy examination and cervical biopsy was not collected from this group. A large number of them (36.7\%) had low grade lesions (CIN I), $1,712(10.6 \%)$ women had high grade lesions $(9.5 \% \mathrm{CIN}$ II and 1.1\% CIN III) and 1,145 (7.1\%) had CC (Table 3).

Calculation of sensitivity, specificity, positive predictive value (PPV) and negative predictive value
Table 2. Demographic and Reproductive Characteristics of Women $(n=1,6147)$

\begin{tabular}{|c|c|c|}
\hline Characteristics & Categories & Number (\%) \\
\hline \multirow[t]{4}{*}{ Age } & Less than 29 years & $3,765(23.3)$ \\
\hline & $30-39$ years & $7,187(44.5)$ \\
\hline & $40-49$ years & $3,740(23.2)$ \\
\hline & 50 years and above & $1,455(9.0)$ \\
\hline \multirow{4}{*}{$\begin{array}{l}\text { Education of } \\
\text { Women }\end{array}$} & No Formal Education & $4,223(26.2)$ \\
\hline & Primary ( 5 years schooling) & $7,038(43.6)$ \\
\hline & SSC (10 years schooling) & $2,504(15.5)$ \\
\hline & HSC (12 years schooling) and above & $1,149(7.1)$ \\
\hline \multirow{3}{*}{$\begin{array}{l}\text { Occupation of } \\
\text { Women }\end{array}$} & House Wife & $15,542(96.3)$ \\
\hline & Service holder & $567(3.5)$ \\
\hline & Labour & $38(0.2)$ \\
\hline \multirow{7}{*}{$\begin{array}{l}\text { Occupation of } \\
\text { Husband }\end{array}$} & Service holder & $6,446(44.1)$ \\
\hline & Business & $5,411(33.5)$ \\
\hline & Farmer & $1,966(12.2)$ \\
\hline & Labour & $899(5.6)$ \\
\hline & Driver & $728(4.5)$ \\
\hline & Not alive & $672(4.2)$ \\
\hline & Unemployed & $25(0.2)$ \\
\hline \multirow{5}{*}{$\begin{array}{l}\text { Monthly family } \\
\text { income }\end{array}$} & Upto Taka 3,000 & $707(4.4)$ \\
\hline & Taka 3,001-6,000 & $2,563(15.9)$ \\
\hline & Taka $6,001-10,000$ & $1,858(11.5)$ \\
\hline & Taka 10,000 and above & $10,623(65.8)$ \\
\hline & Dependent & $396(2.5)$ \\
\hline \multirow[t]{4}{*}{ Parity } & Nuli-para & $460(2.8)$ \\
\hline & Parity 1-2 & $8,169(50.6)$ \\
\hline & Parity 3-5 & $6,746(41.8)$ \\
\hline & Parity 6 and above & $772(4.8)$ \\
\hline \multirow{3}{*}{$\begin{array}{l}\text { Age of } \\
\text { marriage }\end{array}$} & Up to 15 years & $4,820(29.9)$ \\
\hline & 16 to 17 years & $7,188(44.5)$ \\
\hline & 18 years and above & $4,139(25.6)$ \\
\hline \multirow[t]{4}{*}{ Age of delivery } & No children & $293(1.8)$ \\
\hline & $<15$ years & $1,861(11.5)$ \\
\hline & $16-20$ years & $10,415(64.5)$ \\
\hline & 21 years and above & $3,578(22.2)$ \\
\hline
\end{tabular}

*, Percentage within parenthesis,; a) SSC- $\quad$ Secondary School Certificate; b) HSC- Higher Secondary Certificate

(NPV) were done considering histopathology findings as gold standard. Considering CIN as disease the Sensitivity,

Table 3. Histopathology Results of the Women Who had Colposcopy

\begin{tabular}{|c|c|c|c|c|c|c|c|c|c|}
\hline \multirow{2}{*}{$\begin{array}{l}\text { Colposcopy } \\
\text { Findings }\end{array}$} & \multicolumn{8}{|c|}{ Histopathology Result } & \multirow[t]{2}{*}{ Total } \\
\hline & Normal & CIN-I & CIN-II & CIN-III & Carcinoma & Tuberculosis & $\begin{array}{c}\text { Report not } \\
\text { available }\end{array}$ & $\begin{array}{l}\text { Histopathol- } \\
\text { ogy } \\
\text { not Necessary }\end{array}$ & \\
\hline Normal & $0(0.0)$ & $0(0.0)$ & $0(0.0)$ & $0(0.0)$ & $0(0.0)$ & $0(0.0)$ & $0(0.0)$ & $7226(100.0)$ & $7226\left(44.8^{\mathrm{a}}\right)$ \\
\hline CIN-I & $2013(33.9)$ & $2752(46.4 \%)$ & $498(8.4)$ & $104(1.8)$ & $7(0.1)$ & $2(0.03)$ & $558(9.4)$ & $0(0.0)$ & $5934\left(36.8^{\mathrm{a}}\right)$ \\
\hline CIN-II & $338(22.1)$ & $560(36.7)$ & $369(24.2)$ & $97(6.4)$ & $5(0.3)$ & $0(0.00)$ & $159(10.4)$ & $0(0.0)$ & $1528\left(9.5^{\mathrm{a}}\right)$ \\
\hline CIN- III & $20(10.9)$ & $25(13.6)$ & $35(19.0)$ & $69(37.5)$ & $21(11.4)$ & $0(0.00)$ & $14(7.6)$ & $0(0.0)$ & $184\left(1.1^{\mathrm{a}}\right)$ \\
\hline Ca-cervix & $0(0.0)$ & $0(0.0)$ & $0(0.0)$ & $15(1.3)$ & $1114(97.3)$ & $5(0.4)$ & $11(0.9)$ & $0(0.0)$ & $1145\left(7.1^{\mathrm{a}}\right)$ \\
\hline $\begin{array}{l}\text { Colposcopically } \\
\text { Unsatisfactory }\end{array}$ & $69(53.1)$ & $14(20.8)$ & $1(0.7)$ & $1(0.8)$ & $2(1.5)$ & $0(0.00)$ & $43(33.1)$ & $0(0.0)$ & $130\left(0.8^{\mathrm{a}}\right)$ \\
\hline Total & $2440(15.1)$ & $3351(20.8)$ & $903(5.6)$ & $286(1.8)$ & $1149(7.1)$ & $7(0.04)$ & $785(4.9)$ & $7226(44.8)$ & $16147(100.0)$ \\
\hline
\end{tabular}

*Row percentage within parenthesis 
Table 4. Sensitivity, Specificity, PPV and NPV of Colposcopy Considering CIN as Disease

\begin{tabular}{lccc}
\hline Colposcopy & \multicolumn{2}{c}{ Histopathology } & Total \\
& Positive & Negative & \\
\hline Positive & 5,671 & 2,397 & 8,068 \\
Negative & 18 & 7,316 & 7,334 \\
Total & 5,689 & 9,713 & 15,402 \\
Sensitivity & $99.7 \%$ & & \\
Specificity & $75.3 \%$ & \\
PPV & $70.3 \%$ & \\
NPV & $99.8 \%$ & \\
\hline a) PPV- Positive Predictive Value; b) NPV- Negative Predictive Value; \\
c) CIN- Cervical intraepithelial neoplasia
\end{tabular}

Table 5. Sensitivity, Specificity, PPV and NPV of Colposcopy Considering CIN2+ as Disease

\begin{tabular}{lccc}
\hline Colposcopy - & \multicolumn{2}{c}{ Histopathology } & Total \\
& Positive & Negative & \\
\hline Positive & 1725 & 954 & 2,679 \\
Negative & 613 & 12,110 & 12,723 \\
Total & 2338 & 13,064 & 15,402 \\
Sensitivity & $73.80 \%$ & & \\
Specificity & $92.70 \%$ & & \\
PPV & $64.40 \%$ & & \\
NPV & $95.20 \%$ & & \\
\hline
\end{tabular}

a) PPV- Positive Predictive Value; b) NPV- Negative Predictive Value; c) CIN-Cervical intraepithelial neoplasia

Table 6. Influence of Demographic and Reproductive Characteristics on Developing Cervical Pre-Cancer and Cancer

\begin{tabular}{|c|c|c|c|}
\hline Variable & SE & p-value & $\operatorname{Exp}(B)$ \\
\hline \multicolumn{4}{|l|}{ Age } \\
\hline Less than 30 years & 0.002 & 0 & 1.071 \\
\hline \multicolumn{4}{|l|}{30 years and above } \\
\hline \multicolumn{4}{|l|}{ Education of women } \\
\hline Illiterate & 0.024 & 0.007 & 0.938 \\
\hline \multicolumn{4}{|l|}{ Literate } \\
\hline \multicolumn{4}{|l|}{ Socio-economic status } \\
\hline Income $<\mathrm{Tk} .10 \mathrm{~K}$ & 0.022 & 0.014 & 0.947 \\
\hline \multicolumn{4}{|l|}{ Income $>$ Tk. $10 \mathrm{~K}$} \\
\hline \multicolumn{4}{|l|}{ Age of marriage } \\
\hline Less than 18 years & 0.01 & 0.295 & 0.989 \\
\hline \multicolumn{4}{|l|}{18 years and above } \\
\hline \multicolumn{4}{|l|}{ Age of first delivery } \\
\hline Less than 18 years & 0.007 & 0.379 & 0.993 \\
\hline \multicolumn{4}{|l|}{18 years and above } \\
\hline \multicolumn{4}{|l|}{ Parity } \\
\hline $1-3$ child & 0.017 & 0.001 & 1.056 \\
\hline More than 3 Child & & & \\
\hline
\end{tabular}

Table 7. Assocaition between Demographic and Reproductive Factors with CIN and Non-CIN Population

\begin{tabular}{|c|c|c|c|c|}
\hline \multirow[t]{2}{*}{ Variable } & \multicolumn{2}{|c|}{ Histology Findings } & \multirow[t]{2}{*}{ SE } & \multirow[t]{2}{*}{ p-value } \\
\hline & CIN & Non-CIN & & \\
\hline \multicolumn{5}{|l|}{ Age } \\
\hline $\begin{array}{l}\text { Less than } 30 \\
\text { years }\end{array}$ & $1766(38.9)$ & $4417(38.1)$ & 0.984 & 0.321 \\
\hline $\begin{array}{l}30 \text { years and } \\
\text { above }\end{array}$ & $2774(61.1)$ & $7190(61.9)$ & & \\
\hline \multicolumn{5}{|c|}{ Education of women } \\
\hline Illiterate & $987(21.7)$ & $3236(27.9)$ & 63.694 & 0 \\
\hline Literate & $3553(78.3)$ & $8371(72.1)$ & & \\
\hline \multicolumn{5}{|c|}{ Socio-economic status } \\
\hline $\begin{array}{l}\text { Income }<\text { Tk. } \\
10 \mathrm{~K}\end{array}$ & $1511(33.3)$ & 4013 (34.6) & 2.421 & 0.12 \\
\hline $\begin{array}{l}\text { Income > Tk. } \\
10 \mathrm{~K}\end{array}$ & $3029(66.7)$ & $7594(65.4)$ & & \\
\hline \multicolumn{5}{|l|}{ Age of marriage } \\
\hline $\begin{array}{l}\text { Less than } 18 \\
\text { years }\end{array}$ & $3254(71.7)$ & $8754(75.4)$ & 24.023 & 0 \\
\hline $\begin{array}{l}18 \text { years and } \\
\text { above }\end{array}$ & $1286(28.3)$ & $2853(24.6)$ & & \\
\hline \multicolumn{5}{|c|}{ Age of first delivery } \\
\hline $\begin{array}{l}\text { Less than } 18 \\
\text { years }\end{array}$ & $1635(36.9)$ & 4255 (37.3) & 0.179 & 0.672 \\
\hline $\begin{array}{l}18 \text { years and } \\
\text { above }\end{array}$ & $2797(63.1)$ & 7167 (62.7) & & \\
\hline \multicolumn{5}{|l|}{ Parity } \\
\hline 1-3 Childs & $2408(55.0)$ & $5761(51.0)$ & 20.338 & 0 \\
\hline More than 3 child & $1973(45.0)$ & $5545(49.0)$ & & \\
\hline
\end{tabular}

*, Column Percentage within Parenthesis, CIN- Cervical intraepithelial neoplasia; $\mathrm{K}=1,000$, SE- Standard Erro

Specificity, PPV and NPV of colposcopy were found $99.7 \%, 75.3 \%, 70.3 \%$ and $99.8 \%$ respectively. On other hand considering CIN2+ as disease the Sensitivity, Specificity, PPV and NPV of colposcopy were found $73.8 \%, 92.7 \%$, 64.4\% and 95.2\% respectively (Tables 4 and 5$)$.

In the age group of less than 29 years, $19.01 \%$ women developed high grade pre-cancers, this increased to $45.42 \%$ in the $30-39$ years, declined to $25.06 \%$ during $40-49$ years and further declined to $10.51 \%$ after 50 years of age. On the other hand, there was continuous rising trend in case of CC, starting from $3.67 \%$ in the age group of less than 29 years, to $43.44 \%$ after 50 years of age. The occurrences of cervical pre-cancer and cancer were more among the women of 30-49 years. After the age of 35, the proportion of both low grade and high grade lesions declined rapidly whereas $\mathrm{CC}$ remained high among the women of 50 years and above (Figure 1).

The independent influence of different demographic and reproductive characteristics of the women on development of cervical pre-cancer and cancer was assessed (Table 6). Logistic regression analysis revealed that higher age $(p=0.000)$, lower level of education $(p=0.007)$, lower socioeconomic condition $(p=0.014)$, higher parity $(\mathrm{p}=0.001)$ had individual influence on development of cervical pre-cancer and cancer. On the 


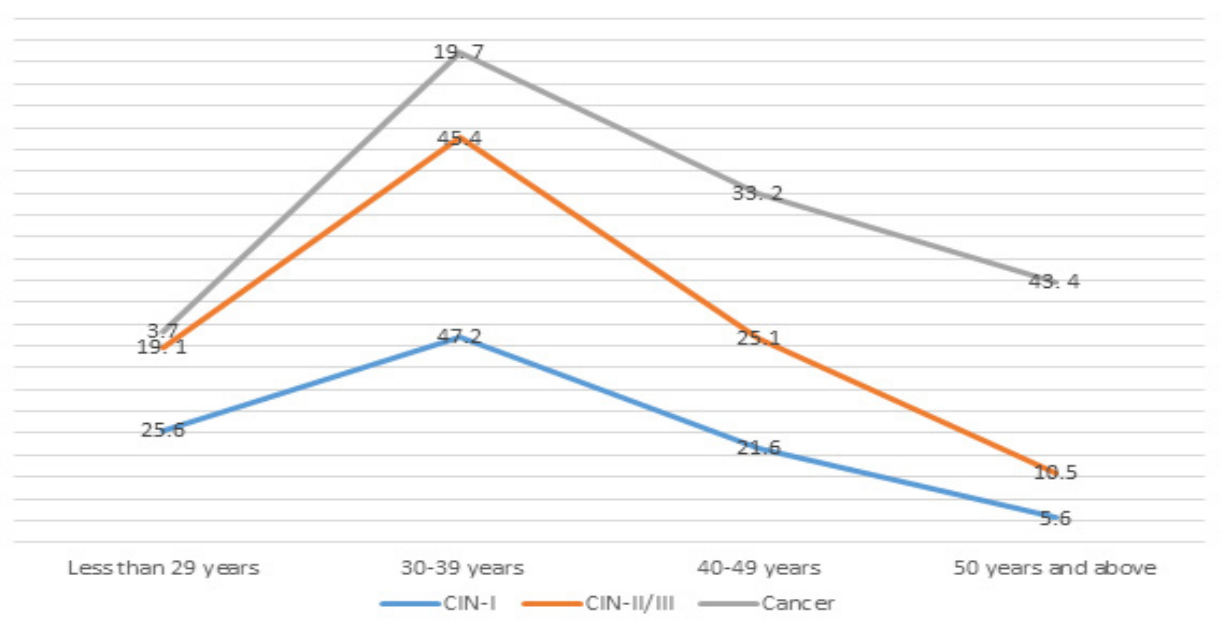

Figure 1. Cervical Pre-Cancer and Cancer among Different Age Groups. The occurrence of cervical pre-cancer and cancer among the women of different age group were shown in Figure 1. We found that the highest $45.4 \%$ pre-cancer among the women of $30-39$ years. On the other hand, there were highest $43.4 \%$ occurrence of cancer after 50 years. At or after 30 years, the rates of cervical pre-cancer declined whereas cervical cancer incidence became high among the women of 50 years and above.

other hand marriage and 1st childbirth at younger age did not show independent influence on developing CIN or CC.

Highly significant association were found between education and CIN $\left(X^{2}=63.694 ; \mathrm{df}=1 ; \mathrm{p}<0.001\right)$, age of marriage and $\mathrm{CIN}\left(\mathrm{X}^{2}=24.023 ; \mathrm{df}=1 ; \mathrm{p}<0.001\right)$ and parity and $\mathrm{CIN}\left(\mathrm{X}^{2}=20.338 ; \mathrm{df}=1 ; \mathrm{p}<0.001\right)$. Insignificant association were found between age and $\mathrm{CIN}\left(\mathrm{X}^{2}=0.984\right.$; $\mathrm{df}=1 ; \mathrm{p}=0.321)$, socio-economic status and $\mathrm{CIN}\left(\mathrm{X}^{2}=\right.$ $2.421 ; \mathrm{df}=1 ; \mathrm{p}=0.120)$ and age of first delivery and CIN $\left(X^{2}=0.179 ; d f=1 ; p=0.672\right)$ (Table 7).

\section{Discussions}

Development of CIN and its progression to CC is one of the important health concerns worldwide. In a developing country like Bangladesh, the huge load of CC patient is referred to tertiary hospitals and institutions. Treatment of this cancer is expensive and requires radical operative procedures, prolonged hospital stay, and/or radiotherapy/ chemotherapy. This research was carried out in a developing country without facility of nationwide high-quality screening programme and $\mathrm{CC}$ vaccination. Therefore, these results are not comparable to the result of a developing country.

Being a large tertiary hospital and major referral centre, BSMMU received a good number of cervical pre-cancer and cancer each year. Trained gynaecologist who have got basic and advanced colposcopy training do the colposcopy of VIA+ve women. Colposcopy findings showed that $10.6 \%$ of the VIA+ve women had high grade disease and $7.1 \%$ had CC. However, histopathology report showed lower prevalence of high grade disease (7.4\%) and CC prevalence remained unchanged. The sensitivity and specificity of colposcopy were $74.1 \%$ and $91.8 \%$ respectively. Sensitivity was about three-fourths, so the test is able to detect three-fourths of the people with disease. Among women with colposcopy diagnosed cervical pre-cancer and cancer, the probability of disease was $60.5 \%$. Women who had normal colposcopy findings, the probability of being disease-free were $95.4 \%$.

A significant number of women below 29 years were included in the program and $19.0 \%$ of women in this group had high grade disease and 3.7\% had CCs. CC screening is a opportunistic screening program in Bangladesh and program does not exclude any married women. Moreover, the legal age of marriage for women in Bangladesh is 18 years, but a large proportion of marriages still take place before the woman reaches her legal age. The mean age at marriage for females is 19.4 in 2011. The BDHS 2014 found that 59 percent of women of 20-24 years were married before age 18 . For this, a good number of women below 29 years came for getting the opportunistic screening services and program could not refuse them.

This study depended both on colposcopy and histological findings. There is well known limitations of these procedures as both are nature dependent and may have individual subjective interpretations (Stoler and Schiffman, 2001; Jeronimo and Schiffman, 2006). In developing countries like Bangladesh other tests for improving sensitivity like HPV DNA test or liquid-based cytology (LBC) are expensive and not rational for economic reasons. However, these limitations were minimized by quality assurance by senior experienced Colposcopists. The histopathology reports were also done by competent pathologists who primarily analysed each histopathology slide and then reconciled differences and reported results by agreement.

This study was performed in unscreened population of Bangladesh and found influence of several demographic and reproductive factors on cervical pre-cancer and cancer. Regression analysis showed significant relation of higher age with development of cervical pre-cancer and cancer. It revealed increasing trend of developing high grade pre-cancers in 30 -39 years age group, followed 
by declined trend to $25.06 \%$ during $40-49$ years and $10.5 \%$ after 50 years of age. On the other hand, there was increasing trend of developing CC, starting from 3.7\% at less than 29 years and $43.4 \%$ after 50 years of age. As most of the target population remained unscreened, cancer prevalence gradually increased with age reflecting conversion of high grade lesions to cancer among elderly population. With increasing screening this situation is expected to be changed. Östör (1993) also showed a rising trend in unscreened population, as CIN III prevalence peaked in the 55 to 59 age group and declined in the older age groups, and this trend could be due to spontaneous regression of $\mathrm{CIN}$ or progression to invasive carcinoma in this age group. In this study, about $80 \%$ of high grade pre-cancers and $96 \%$ of cancers occurred after 30 years. This finding justifies and supports the government strategy of initiation of screening at the age of 30 years in Bangladesh. About $52.9 \%$ of the CC occurs between $30-49$ years of age and remaining $43.4 \%$ occurred after 50 years of age indicates that both premenopausal and postmenopausal women are equally susceptible to have CC. Only $9 \%$ of the VIA positive women were more than 50 years of age and among them about $43.4 \%$ had CC. This indicated low participation of elderly women in this opportunistic screening programme and improved participation of this group will improve pickup of more cancer cases.

A study of Brazil and several studies in India revealed increasing prevalence rate of invasive carcinoma with age (d'Ottaviano-Morelli et al., 2004; Reddy et al., 2013;Ramachandran et al., 2016; Akshatha et al., 2017). A study in Egypt also showed old age as a significant risk factor for CC (El-Moselhy et al., 2016). All these findings indicated that screening should be initiated around 30 years of age and women around 40 years and elderly female should get special emphasis in developing countries during CC screening.

In the current study, marriages at younger age and $1 \mathrm{st}$ childbirth have no independent influence on development of cervical pre-cancer and cancer. However, studies in Iraq and Assam, India reported marriage at or less than 18 years was strongly associated with cervical pre-cancer (Khalaf et al., 2015; Paul et al., 2011) and case control study in Egypt also reported young age at marriage ( $<18$ years) as a significant risk factor for CC (El-Moselhy et al., 2016).

In the present study, among the demographic and reproductive characteristics, lower level of education (0.007), lower socioeconomic condition $(\mathrm{p}=0.014)$, higher parity $(\mathrm{p}=0.001)$ had individual influence on development of cervical pre-cancer and cancer. Less than one-fourth of the women had secondary education and above and majority of the women were housewives. This reflected a low level of women empowerment in Bangladesh, which may be related to lack of awareness and less health care seeking behavior making them vulnerable to acquire cervical pre-cancer and cancer. A study in Egypt concluded low education level as an important socio-demographic risk factor for CC (El-Moselhy et al., 2016). Study in Assam reported the influence of economic status, on cervical pre-cancer and cancer (Paul et al., 2011). Policy makers should give special emphasis for improving education and job opportunity of women which should further improve their socio-economic condition and empowerment.

It was observed that $7518(56.6 \%)$ women having parity more than 3 had significant association with development of cervical pre-cancer and cancer. One large population based longitudinal study in Denmark found parity as an important cofactor for developing high-grade cervical disease (Jensen et al., 2013). A pooled analysis of ten case-control studies by the IARC involving eight developing countries of Africa, South America, Asia, and Europe found that parity increased the risk of both invasive and in-situ carcinoma of the cervix (Munoz et al., 2002). Increased hormone levels and impaired immune response during pregnancy have been suggested as risk factor for cervical pre cancer and cancer (Appleby et al., 2006). Moreover, positioning of the transformation zone on the ecto-cervix for longer period in multiparous women facilitates direct exposure to HPV and potential cofactors (Autier et al., 1996). All these information indicate that parity is consistently associated with CC risk and declining multi-parity should have a positive impact in reducing CC in developing countries like Bangladesh. Bangladesh is a highly populated country and at least 20 million population need screening. The GOB is proactive to provide high quality family planning services for limiting childbirth. However more efforts need to be given on this aspect as parity 3 and above is still common in this country.

Prevalence and risk factors of cervical pre-cancer and cancer in Bangladesh has not been described by any population based study in Bangladesh. This study included information from different districts covering large areas of the country.

Government has taken the stewardship to scale up the screening program all over the country and recently developed CC strategy and costed action plan. This will strengthen the program to serve the women.

The results from the current should must be considered in light of certain limitations. Firstly, the study was carried out in the colposcopy clinic of BSMMU. All data were kept in prescribed colposcopy register, there were limitation of information about some variables like rural, urban, stage of cancer of the screen positive women. Moreover the information on menopause and tobacco habit were not considered. Secondly, there is a possibility of re-call bias about some data, such as, age of marriage, age of first delivery etc. Furthermore a population based epidemiological study in Bangladesh on CC should be performed to find out the impact of socio-demographic and reproductive factors on $\mathrm{CC}$.

In conclusion, this study found that elderly women and women with low socio-economic condition, low education level and high parity were at higher risk of developing CC. The current national program is opportunistic and continuing at the primary, secondary, and tertiary level health care facilities. In order to improve screening coverage specific health interventions should be carried out. The programme should give special importance to elderly women, women with low socio-economic condition, low education level and high parity during screening to have better detection rate at shorter duration. 
There are resource limitations to implement $\mathrm{CC}$ screening program and special attention to these women will pick up more pre-cancer and early cancer. In addition to this, vaccination program for adolescent girls should be carried out. Moreover, woman's education and empowerment are important socio-demographic factors and need special attention to improve awareness and health seeking behavior.

\section{References}

Akshatha C, Arul P, Shetty S (2017). Prevalence and comparison of cervical cytology abnormalities in postmenopausal and elderly women: An experience from tertiary care hospital. $J$ Med Soc, 31, 23-7.

Autier P, Coibion M, Huet F, Grivegnee AR (1996). Transformation zone location and intraepithelial neoplasia of the cervix uteri. Br J Cancer, 74, 488-90.

Bray F, Ren JS, Masuyer E, Ferlay J (2013). Estimates of global cancer prevalence for 27 sites in the adult population in 2008 . Int $J$ Cancer, 132, 1133-45.

d'Ottaviano-Morelli MG, Zeferino L, Cecatti JG, Terrabuio DR, Martinez EZ (2012). Prevalence of cervical intraepithelial neoplasia and invasive carcinoma based on cytological screening in the region of Campinas, São Paulo, Brazil. Cadernos de Saúde Pública, 20, 153-9.

El-Moselhy EA, Borg HM, Atlam SA (2016). Cervical Cancer: Sociodemographic and clinical Risk Factors among Adult Egyptian Females. Adv Oncol Res Treat, 1, 1-7.

Ferlay J, Ervik M, Lam F, et al (2018). Global cancer observatory: Cancer today. Lyon, France: International Agency for Research on Cancer.[Internet]. Available from: https://gco.iarc.fr/today, accessed [Accessed 2019 Jan 05].

Holme F, Kapambwe S, Nessa A, et al (2017). Scaling up proven innovative cervical cancer screening strategies: Challenges and opportunities in implementation at the population level in low-and lower-middle- income countries. Int J Gynaecol Obstet, 138, 63-8.

Jensen KE, Schmiedel S, Norrild B, et al (2013). Parity as a cofactor for high-grade cervical disease among women with persistent human papillomavirus infection: a 13-year follow-up. Br J Cancer, 108, 234-9.

Jeronimo J, Schiffman M (2006). Colposcopy at a crossroads. Am J Obstet Gynecol, 195, 349-53.

KhalafMK, Rasheed FA, Hussain SA(2015). Association between early marriage and other socio-medical characteristics with the cervical Pap smear results in Iraqi women. Adv Sexual Med, 5, 73-82.

Lizano M, Berumen J, Carranca A (2009). HPV-related carcinogenesis: Basic Concepts, Viral Types and Variants. Arch Med Res, 40, 428-34.

Muñoz N, Franceschi S, Bosetti C, et al (2002). Role of parity and human papillomavirus in cervical cancer: the IARC multi-centric case-control study. Lancet, 359, 1093-1101.

National Institute of Population Research and Training (NIPORT), Mitra and Associates, and ICF International. 2016. Bangladesh Demographic and Health Survey (2014). Dhaka, Bangladesh, and Rockville, Maryland, USA: NIPORT, Mitra and Associates, and ICF International.

Nessa A, Rashid MH, Ferdous NE, Chowdhury A (2013). Screening for and management of high-grade cervical intraepithelial neoplasia in Bangladesh: A cross-sectional study comparing two protocols. J Obstet Gynaecol Res, 39, 564-571.

Nessa A, Hussain MA, Rahman JN, et al (2010). Screening for cervical neoplasia in Bangladesh using visual inspection with acetic acid. Int J Gynaecol Obstet, 111, 115-8.

Östör AG (1993). Natural history of cervical intraepithelial neoplasia: a critical review. Int J Gynecol Pathol, 12, 186-92.

Paul SB, Tiwary BK, Choudhury AP (2011). Studies on the epidemiology of cervical cancer in Southern Assam. Assam Univ J Sci Technol, 7, 36-42.

Rajkumar T, Cuzick J, Appleby P, et al (2006). Cervical carcinoma and reproductive factors: Collaborative reanalysis of individual data on 16,563 women with cervical carcinoma and 33,542 women without cervical carcinoma from 25 epidemiological studies. Int J Cancer, 119, 1108-24.

Ramachandran M, Kannan A, Kiyam W, Prasaad PR, Rao GB (2016). PAP smear findings in Premenopausal and Postmenopausal Women- A Comparative Study. Res J Med Allied Sci, 1, 14-21.

Reddy BC, Rao AR, Madhavi KVP, Ravikumar BP, Padala A (2013). Study of cervical cytology in menopausal women - In a maternity and general Hospital, Hyderabad, Andha Pradesh. J Evolution Med Dent Sci, 2, 6824-30.

Remschmidt C, Kaufmann AM, Hagemann I, et al (2013). Risk factors for cervical human papillomavirus infection and high-grade intraepithelial lesion in women aged 20 to 31 years in Germany. Int J Gynecol Cancer, 23, 519-26.

Stoler MH, Schiffman M (2001). Interobserver reproducibility of cervical cytologic and histologic interpretations: realistic estimates from the ASCUSLSIL Triage Study. JAMA, 285, 1500-5.

Tainio K, Athanasiou A, Tikkinen K, et al (2018). Clinical course of untreated cervical intraepithelial neoplasia grade 2 under active surveillance: systematic review and meta-analysis. $B M J$ (Clinical research ed.), 360, k499. doi:10.1136/bmj. k499.

World Health Organization. Reproductive Health and Research. and World Health Organization. Chronic Diseases and Health Promotion (2006). Comprehensive cervical cancer control: a guide to essential practice. Geneva: World Health Organization, http://www.who.int/ reproductive-health/ publications/cervical_cancer_gep/text.pdf.

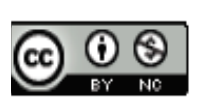

This work is licensed under a Creative Commons AttributionNon Commercial 4.0 International License. 